\title{
Impact of the COVID-19 pandemic on clinical research
}

Katherine R. Tuttle $\mathbb{1}^{1,2}$

The COVID-19 pandemic has placed a tremendous strain on sustaining the clinical research enterprise and will also likely affect key study outcomes; these effects must be considered during data analysis and interpretation. Nevertheless, the responses to the pandemic have also introduced innovations that will advance the conduct of clinical research.

COVID-19 is with us for the long haul, a marathon that we will run for months or years to come

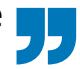

'Providence Medical Research Center, Providence Health Care, Spokane, WA, USA.

${ }^{2}$ Nephrology Division, Kidney Research Institute and Institute of Translational Health Sciences, University of Washington, Spokane and Seattle, WA, USA.

e-mail:katherine.tuttle@ providence.org

https://doi.org/10.1038, s41581-020-00336-9
The first recognized case of severe acute respiratory syndrome coronavirus 2 (SARS-CoV-2) infection leading to coronavirus disease 2019 (COVID-19) in the USA occurred during late January 2020 in the state of Washington ${ }^{1}$. Our state was hit hard by the outbreak that followed, as hospitals and emergency medical services became overwhelmed by severely ill patients in the major health-care hubs ${ }^{2-5}$. We first had a sprint, from March through to May 2020 when elective procedures and in-person patient visits were halted to reduce the risk of viral transmission, conserve personal protective equipment (PPE) and make more health-care workers available for the enormous clinical impact of COVID-19. As initial social distancing and other efforts to contain the virus dampened the spread, we began to gradually re-open in health-care systems and society at large. However, this was soon followed by another uptick in cases beginning in June 2020 that required backtracking to more restrictive measures. It is now clear that COVID-19 is with us for the long haul, a marathon that we will run for months or years to come.

SARS-CoV-2 infection spreads via extremely contagious respiratory droplets 6 . COVID-19 is commonly a mild upper respiratory illness, but a substantial minority of patients develop severe bilateral pneumonia leading to hospitalization for supplementary oxygen and supportive care, or respiratory failure requiring mechanical ventilation ${ }^{7-9}$. SARS-CoV-2 infection also spreads from the lungs to other organs ${ }^{6}$. Acute kidney injury is common in patients with COVID-19 and may be due to viral infiltration or other kidney injuries caused by a systemic inflammatory response, hypotension or nephrotoxins $\mathrm{s}^{2-4,7,10}$. As a result, clinical nephrology services have been overwhelmed by the acute dialysis needs of patients hospitalized with COVID-19. Many of us, no matter how senior or focused on academic work, have been called to clinical service. I was the only nephrologist still in practice who knew how to implement acute peritoneal dialysis should we run short of resources for continuous kidney replacement therapy. This important skill has all but disappeared in contemporary nephrology practice, despite its practicality and effectiveness in acute care settings.

I began my career as an intern in 1982 when AIDS had started to wreak havoc at Northwestern Memorial Hospital in Chicago. I cared for more pneumocystis pneumonia than pneumococcal pneumonia and more Kaposi's sarcoma than breast cancer. Nearly half of the medical services were AIDS wards when I finished my residency in 1985 . HIV was identified as the cause around that time. However, intense research efforts led to HIV testing and novel treatment options, which have dramatically reduced the number of full-blown AIDS cases and turned HIV infection into a mostly manageable chronic condition. There are many lessons from HIV/AIDS that have informed my current thinking and response to COVID-19.

The Providence St Joseph Health hospitals in Washington state have had $>7,000$ admissions for COVID-19 as of 20 July 2020, and more come each day. Within this health-care system, I am executive director for research in the Providence Health Care region and, in this role, I rapidly turned old lessons from the HIV/AIDS era into new actions. Our overarching goal was to address the critical needs of COVID-19 research while maintaining research for essential concerns across other therapeutic areas in both adult and paediatric medicine. The main priority was to open the platform clinical trial of anti-viral treatments sponsored by the National Institutes of Allergy and Infectious Diseases/National Institutes of Health (NIAID/NIH), which required redirection of clinical research resources from other therapeutic areas to COVID-19 and a rapid administrative response. Our regulatory group and Institutional Review Board prepared, reviewed and approved the study protocol and informed consent form within 3 days over a weekend. Our budget and contracting groups similarly moved with record speed. As a result, our site was among the first ten sites activated on the initial NIAID/NIH clinical trial of remdesivir versus placebo. Our first participant was enrolled just 5 days after we received the study protocol. 
Table 1 | Clinical research responses to the COVID-19 pandemic

\begin{tabular}{|c|c|c|}
\hline $\begin{array}{l}\text { Research } \\
\text { response }\end{array}$ & COVID-19 & Non-COVID-19 conditions \\
\hline $\begin{array}{l}\text { Clinical trial } \\
\text { priorities }\end{array}$ & $\begin{array}{l}\text { Anti-viral treatment protocols } \\
\text { prioritized }\end{array}$ & Resources redirected \\
\hline $\begin{array}{l}\text { Regulatory and } \\
\text { Institutional } \\
\text { Review Board }\end{array}$ & $\begin{array}{l}\text { Expedited preparation, review } \\
\text { and approval }\end{array}$ & $\begin{array}{l}\text { Sponsors and sites rapidly } \\
\text { developed and approval } \\
\text { received for remote trial } \\
\text { conduct }\end{array}$ \\
\hline $\begin{array}{l}\text { Sponsor and } \\
\text { financial } \\
\text { management }\end{array}$ & $\begin{array}{l}\text { Accelerated contracts and } \\
\text { budget }\end{array}$ & $\begin{array}{l}\text { Resources redirected to } \\
\text { support participant outreach } \\
\text { and to deploy technologies } \\
\text { for remote trial conduct }\end{array}$ \\
\hline Study timelines & $\begin{array}{l}\text { First participant enrolled } \\
<1 \text { week from protocol receipt }\end{array}$ & $\begin{array}{l}\text { Enrolment periods extended } \\
\text { if in-person visit required }\end{array}$ \\
\hline $\begin{array}{l}\text { Investigators and } \\
\text { coordinators }\end{array}$ & $\begin{array}{l}\text { Multi-specialty team: infectious } \\
\text { disease, pulmonary-critical } \\
\text { care, hospital medicine, } \\
\text { nephrology and cardiology }\end{array}$ & $\begin{array}{l}\text { Roles and responsibilities: } \\
\text { team ethos, flexibility and } \\
\text { cross-training }\end{array}$ \\
\hline $\begin{array}{l}\text { Patient access and } \\
\text { on-study culture }\end{array}$ & $\begin{array}{l}\text { A study for every patient: } \\
\text { daily huddle for case review; } \\
\text { remote consenting; consenting } \\
\text { by legally authorized } \\
\text { representative; informed } \\
\text { consent forms translated into } \\
\text { five languages to match patient } \\
\text { demographics }\end{array}$ & $\begin{array}{l}\text { Sustain engagement: } \\
\text { frequent outreach; provide } \\
\text { updates; answer questions; } \\
\text { address concerns; remote } \\
\text { technologies for study } \\
\text { participation; survey about } \\
\text { experiences and perspectives } \\
\text { for study conduct }\end{array}$ \\
\hline $\begin{array}{l}\text { COVID-19-related } \\
\text { considerations }\end{array}$ & $\begin{array}{l}\text { Portfolio: interventional } \\
\text { treatments for full spectrum of } \\
\text { patients; observational studies } \\
\text { for epidemiology; biobanking; } \\
\text { serology testing }\end{array}$ & $\begin{array}{l}\text { Study conduct: missed visits } \\
\text { and data; interruption of } \\
\text { study treatment; protocol } \\
\text { deviations; adverse events; } \\
\text { impact on key outcomes }\end{array}$ \\
\hline
\end{tabular}

COVID-19, coronavirus disease 2019.

Research groups from other therapeutic areas were quickly deployed, trained and certified by NIAID/NIH to ensure that enough investigators and study coordinators were available to manage this intense clinical trial activity. Our COVID-19 investigators are a multi-specialty team consisting of experts in infectious diseases, pulmonary and critical care, hospital medicine and nephrology. Similarly, research coordinators who normally manage studies in cardiology and nephrology were moved onto the COVID-19 team. We meet in a daily huddle to review all hospital admissions for COVID-19 with the goal of having a study option for every patient. The NIAID/NIH platform trial is continuing and we have since activated other new protocols for serology testing, biobanking and therapeutic interventions in those who have been excluded from the NIAID/NIH protocols, such as patients with an estimated glomerular filtration rate of $<30 \mathrm{ml} / \mathrm{min} / 1.73 \mathrm{~m}^{2}$. Informed consent forms are currently available in five languages, and we have implemented Institutional Review Board-approved consent via remote technologies and using legally authorized representatives.

The COVID-19 pandemic has placed a tremendous strain on the clinical research enterprise. With the redirection of resources and temporary halting of in-person visits, studies in other therapeutic areas have been unavoidably constrained. However, the COVID19 response has also introduced innovations that have advanced our overall conduct of clinical research (TABLE 1). Although recruitment and enrolment for

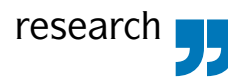

most other studies stopped during the early stages of the pandemic, both our study sponsors and sites developed new approaches to conduct remote visits by telehealth, use home-based testing or monitoring technologies, and provide curbside or courier pick-up and delivery of participant samples and investigational products. Our research leaders, investigators and staff have made concerted efforts to provide study updates to participants - by telephone, email and through the electronic health record portal - during and after the pause in the studies. We re-opened for in-person visits on 18 May 2020 under strict enforcement of clinical protocols for viral infection prevention and the use of PPE according to the guidelines established by our health-care system. Study participants are given the option of a remote visit whenever possible. Every person who enters the clinical research centre is screened for COVID-19 symptoms, fever and potential exposure. Masks and physical distancing are required for all in-person interactions and no visitors are allowed, except for one parent in the case of paediatric patients, or one carer in the case of patients with disabilities.

The enrolment rates for our research programme are now similar to those recorded pre-pandemic. To the best of our knowledge, we have sustained retention in the ongoing studies. We will survey participants about their experiences and perspectives to facilitate research despite the risks associated with COVID-19. Notably, we must be cognizant that COVID-19 might affect key study outcomes. For example, SARS-CoV-2 infection could worsen glycaemic control in persons with diabetes, raise or lower blood pressure in those with hypertension, or accelerate progression of chronic kidney disease. Adverse events, particularly acute illnesses, hospitalizations and mortality may be caused by the viral infection or by deferral of care due to fear of contracting it. Participants are also likely to have changed their lifestyles to minimize contact with others, which may also affect outcomes. These are crucial considerations for study analysis and interpretation. Potential confounding may be addressed by examining pre-and post-pandemic outcome rates and COVID-19 surveillance with control for evidence of exposure or infection entered into data analysis plans. Nevertheless, with proactive measures, it is feasible to maintain interest, participation and quality in clinical research.

Investigators, coordinators and clinicians have a renewed sense of urgency and purpose to use science to solve problems that are important to patients and the public. We do get tired at times, and burnout is a real risk. Yet, we move forward with mutual support, encouragement and focus on tangible goals to keep making research better. All of these are positive changes that we will retain long after the COVID-19 pandemic subsides.

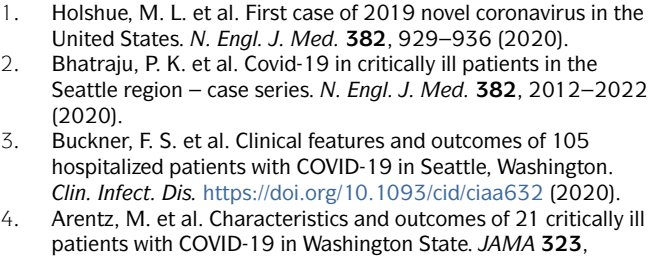


5. Yang, B. Y. et al. Clinical characteristics of patients with coronavirus disease 2019 (COVID-19) receiving emergency medical services in King County, Washington. JAMA Netw. Open 3, e2014549 (2020).

6. Tay, M. Z., Poh, C. M., Rénia, L., MacAry, P. A. \& Ng, L. F. P. The trinity of COVID-19: immunity, inflammation and intervention. Nat. Rev. Immunol. 20, 363-374 (2020).

7. Richardson, S. et al. Presenting characteristics, comorbidities, and outcomes among 5700 patients hospitalized with COVID-19 in the New York City area. JAMA 323, 2052-2059 (2020).
8. Grasselli, G et al. Baseline characteristics and outcomes of 1591 patients infected with SARS-CoV-2 admitted to ICUs of the Lombardy region, Italy. JAMA 323, 1574-1581 (2020).

9. Zhou, F. et al. Clinical course and risk factors for mortality of adult inpatients with COVID-19 in Wuhan, China: a retrospective cohort study. Lancet 395, 1054-1062 (2020).

10. Hirsch, J. S. et al. Acute kidney injury in patients hospitalized with COVID-19. Kidney Int. 98, 209-218 (2020).

\section{Competing interests}

The author declares no competing interests. 